\title{
Production and consumption-based water dynamics: A longitudinal analysis for the EU27
}

\author{
Ana Serrano $^{+*}$ and Javier Valbuena ${ }^{++}$ \\ ${ }^{+}$Department of Economic Analysis, Faculty of Economics and Business Studies. \\ Gran Via 2, 50005 Zaragoza, Spain. asergon@unizar.es \\ ${ }^{++}$Independent researcher. valbuena.javier@gmail.com
}

\begin{abstract}
This paper investigates the relationship between economic development and water pressures using a global Multiregional Input-Output model (MRIO) dataset that takes into account the increasingly connected global supply chains underlying the economic systems. In particular, we analyse differences in water indicator outcomes by income level amongst European Union countries (EU27) from 1995 to 2008, focusing specifically on production and consumption-based water metrics for the member states. We use panel fixed effects regressions to study the dynamics of adjustment of water resources alongside controlling for individual country heterogeneity. Our main results indicate that the effects differ substantially depending on the approach used for measurement, especially when we conditioned on the country economic development, indicating opposite trajectories of water consumption and per capita gross domestic product (GDP). Furthermore, the analysis of the main components associated to water indicators highlight the role of water embodied in trade flows as the transmission mechanisms of the main effects. In particular, our estimates suggest that the growth path followed by the most developed areas in the EU27 is based on the externalisation of the environmental burden over the less developed European partners, and external developing countries. On the policy front, our findings call for the implementation of integrated water resources management, technological specific policies and the corresponding environmental regulation to combine the conservation of water ecosystems and sustainable economic growth at the national, supranational and global levels.
\end{abstract}

Keywords: water dynamics, production-based, consumption-based, MRIO, panel data

*Corresponding author: Department of Economic Analysis, Faculty of Economics and Business Studies. Gran Via 2, 50005 Zaragoza, Spain. E-mail: asergon@unizar.es 


\section{Introduction}

The extensive economic growth experienced by the world during the twentieth century, and its associated processes as structural change, urbanization or technological development, have profoundly affected the relationship of human civilizations with natural ecosystems. The growing extraction of natural resources, the intensification of pollution and the extinction of biodiversity have brought the negative sides of modern economic growth to light. As an example, during this period global material use increased eightfold (Krausmann et al., 2009) and $\mathrm{CO}_{2}$ emissions by a factor of 13 (Smil, 2008). In this framework, the understanding of global environmental pressures and their interactions with economic growth is currently one of the major concerns of international institutions (UNEP, 2011). Scientific literature has also assessed the relationships between economic activity and environmental impacts, focusing mostly on materials use and greenhouse emissions (recent studies can be found in: Galli et al., 2017; Naqvi and Zwickl, 2017; Steinberger et al., 2013; Stern, 2010). In the case of water, this type of studies were mostly developed during the last fifteen years, given the availability of new international and comparable information on the use and consumption of water resources (some examples of these databases are: AQUASTAT, Water Footprint Network, EUROSTAT, etc.).

Since the 1900s to the end of the century water use rose sixfold (WMO, 1997). Population and economic growth have been pointed out as two of the main contributors to this upward trend (Vörösmarty et al., 2005; WWAP, 2015). As a result, pressures on water resources have exacerbated. Currently as much as $25 \%$ of freshwater withdrawals exceed accessible supplies (Vörösmarty et al., 2005), and according to UN-Water (2006) "almost one-fifth of the world's population, live in areas of physical scarcity, and 500 million people are approaching this situation. Another 1.6 billion people, or almost one quarter of the world's population, face economic water shortage”.

This growing institutional awareness and the collection of global water data have led to an intense spread of the studies on the temporal patterns of water availability and use, and their driving forces, particularly in the last decade. Some of these works test the existence of the Environmental Kuznets Curve (EKC) on water withdrawal and water consumption (Cole, 2004; Duarte et al., 2013; Gupta, 2015; Katz, 2015), or 
check the effectiveness of water management policies (Ziolkowska and Ziolkowski, 2016). All this literature is based on the production-based approach, i.e., it only considers the water directly abstracted or consumed in the countries. Thus, these assessments do not account for the volume of water embodied in trade flows, a component especially important in a highly globalized context. In particular, as Chen and Chen (2013) show, water embodied in international trade represented about 30\% of total water use in the world in 2004. In this line, the concept of virtual water, defines the volume of water required to produce a commodity, i.e., the water embodied into a product (Allan, 1993). It informs on the environmental impact of consuming this product and it is closely linked to the water footprint (WF). Introduced by Hoekstra and Hung (2002), the WF reflects the virtual water content of all goods and services directly and indirectly consumed by people. More concretely, the WF of a nation is the freshwater embedded in the production process of goods and services consumed by its population. It is a consumption-based metric, which includes the total consumption of water, regardless of whether it comes from domestic sources or it is embodied in trade flows (Hoekstra et al., 2011). The WF can be calculated using the bottom-up or the top-down methodologies. The former has been employed in specific studies that use the WF to determine the existence of decoupling (Gilmont, 2016, 2015), test cross-sectional EKCs by means of econometric techniques (Miglietta et al., 2016; Sebri, 2015) or analyse the drivers of the WF using decomposition techniques (Zhao and Chen, 2014). More recently, the top-down approach has been applied to examine the relationship between economic activity and water pressures (Wang et al., 2016).

This paper is concerned with the links between economic development and water consumption. In particular, we analyse differences in water indicator outcomes by per capita gross domestic product (GDP) amongst European Union countries (EU27) during the period 1995-2008, focusing specifically on production-based and consumed-based water consumption values measured at the country level. Recent studies, although limited by the cross-sectional nature of the analysis, have underlined the existence of varying and potentially opposite effects economic growth can have on water resources depending on the aforementioned water consumption account of interest (Wang et al., 2016; Wang and Zimmerman, 2016). To the best of our knowledge, we contribute to the existing literature as the first study that combines a 
global Multiregional Input-Output model (MRIO) and longitudinal analysis to offer a temporal perspective on the interdependencies of economic development and the dynamics of water resources. The main advantage of using longitudinal analysis, which tracks the same type of information on the same countries at multiple points in time, is that allows to study dynamic relationships and to account for differences across countries. Therefore, we additionally present estimates modelling the presence of country economic heterogeneity that provide a more precise understanding of the adjustment mechanisms of water indicators.

More concretely, we use a global MRIO extended to water resources. MRIO models are powerful tools that trace all the economic linkages from production to final consumption in global supply chains, providing a comprehensive framework to track down (at the sector and country levels) the economic interdependencies behind environmental impacts. As a result, they allow quantifying the anthropogenic production and consumption responsibilities on the pressures on water resources. Furthermore, considering that impacts on water occur at a local scale via production activities, but reach a global level through international trade, it will also be possible to disentangle the domestic and foreign components driving water consumption. Despite their explanatory power, MRIO models present two main drawbacks compared to bottom-up approaches. First, they require sectorial data, involving some loss in disaggregation detail. Secondly, they usually cover a limited number of years (Galli et al., 2013). In accordance with our research question it is critical to consider the volume of water embodied in trade flows, and therefore we will quantify the water metrics applying the top-down methodology. These water indicators will serve as the main dependent variables considered in the panel data econometric model to measure the role of per capita GDP as the most relevant driver of water impacts through production, consumption and trade.

We will carry out the analysis by considering the EU27 as a case study. Drawing on data from the World Development Indicators of the World Bank (World Bank, 2016) and the World Input Output Database (WIOD), we observe that with only $7 \%$ of the world population and 4\% of global renewable water resources, EU27 represented about 27\% of global GDP in 2008 and imported around 32\% of the water embodied in all international trade flows. The relevance of water embodied in trade together with the heterogeneity in this region, with countries at different stages of development, 
makes the EU27 a good framework to contrast production and consumption-based water indicators and the impact of economic development. In this study water is identified with blue water, defined as the freshwater from surface or ground sources (Hoekstra et al., 2011) that can be directly managed by human activity. There are interesting studies on the quantification of the EU water impacts using input-output modelling (Lutter et al., 2016; Serrano et al., 2016; Steen-Olsen et al., 2012; Vanham and Bidoglio, 2013). While the previous works focus on a specific year, our study offers for the first time a dynamic perspective for the period from 1995 to 2008. These years are particularly relevant. First, with an average annual growth over $2 \%$, the EU experienced an intense and sustained economic growth. Secondly, the progressive incorporation of new member states during these years allows comparison of water impacts by distinct income patterns. Thus, the temporal perspective will enable us to contrast trends on the production and consumption-based metrics, evaluating the offshoring of environmental damage via intra- and extra-European trade flows.

The rest of the paper is organized as follows. Section 2 describes the data and methods used. Section 3 shows the main results. First, sub-section 3.1 proceeds with a descriptive analysis on the water consumption trends observed in the EU27, using the indicators obtained with the extended MRIO model. Then, in sub-section 3.2 we apply a panel data econometric model to quantify the impact of per capita GDP on the different water consumption metrics. Finally, the paper closes discussing the relevant findings and presenting the main conclusions of the study.

\section{Data and methodology}

Our analysis uses MRIO tables for the period 1995-2008 taken from the WIOD. They inform on the economic linkages along supply chains among 35 sectors in 41 areas (40 countries and the Rest of the World (RoW)), differentiating intermediate and final demands (consumption by households, non-profit organizations serving households, government, capital investment, and changes in inventories) (Dietzenbacher et al., 2013; Timmer et al., 2015). This database is particularly suitable for the study of the dynamics of water resources in the EU. First, it offers information for its 27 members. Second, it provides data on direct water consumption (DW) comparable to the MRIO tables. Finally, the availability of environmental information and tables for 15 years 
allows studying the impact of economic activity on water resources from a temporal perspective. This is merged by the countries' ISO code with recent economic and social indicators, namely GDP (expressed at constant 2010US\$) and population data (P hereafter) taken from the World Development Indicators of the World Bank (World Bank, 2016).

MRIO tables are environmentally extended to water resources using data on water consumption from the WIOD environmental accounts (Genty et al., 2012). More concretely, we use the specific information on blue water, defined as fresh surface and groundwater that can be withdrawn from lakes, rivers and aquifers.

International institutions such as the Organisation for Economic Co-operation and Development (OECD), the United Nations (UN) or Eurostat have contributed to the development and standardisation of input-output tables. Input-output modelling and its extensions have been widely used as a tool for the analysis of macroeconomic, social and environmental impacts of multi-sectorial, and more recently, supranational economic activities. In this regard, one of the major contributions of global MRIO models is their description of global supply chains that allow measuring the responsibility for environmental burdens and the role of international trade (Tukker and Dietzenbacher, 2013). More concretely, the use of WIOD will enable separating the producer and consumer responsibilities on water consumption using a temporal perspective.

Departing from the basic input-output equation proposed by Leontief (1941), we obtain total output by adding intermediate and final demands in a multiregional framework:

$$
\mathbf{x}=\mathbf{A x}+\mathbf{y}
$$

Being $\mathbf{x}$ a vector of total output per country and sector, $\mathbf{A}$ the multiregional matrix of technical coefficients and $\mathbf{y}$ the vector of final demands. The total output can be also expressed as a function of the Leontief inverse defined for the global economy as:

$$
\mathbf{x}=(\mathbf{I}-\mathbf{A})^{-1} \mathbf{y}=\mathbf{L y}
$$

Following Proops (1988) the MRIO model is environmentally extended. We define a diagonal matrix $(\widehat{\mathbf{W}})$ with information of the water directly consumed per unit of total 
output in each sector and country (water intensity). Pre-multiplying equation (2) by $\widehat{\mathbf{W}}$ and applying the demand breakdown proposed in Cazcarro et al. (2012), we analytically obtain the MRIO model extended to water resources:

$$
\begin{aligned}
& \mathbf{W}=\left(\begin{array}{ccccc}
\mathbf{W}_{11} & \mathbf{W}_{12} & \cdot & \cdot & \mathbf{W}_{1 \mathbf{r}} \\
\mathbf{W}_{21} & \mathbf{W}_{22} & \cdot & \cdot & \mathbf{W}_{2 \mathbf{r}} \\
\cdot & \cdot & \cdot & \cdot & \cdot \\
\mathbf{W}_{\mathbf{s} 1} & \cdot & \mathbf{W}_{\mathrm{ss}} & \cdot & \mathbf{W}_{\mathrm{sr}} \\
\cdot & \cdot & \cdot & \cdot & \cdot \\
\mathbf{W}_{\mathrm{r} 1} & \mathbf{W}_{\mathrm{r} 2} & \cdot & \cdot & \mathbf{W}_{\mathrm{rr}}
\end{array}\right)=
\end{aligned}
$$

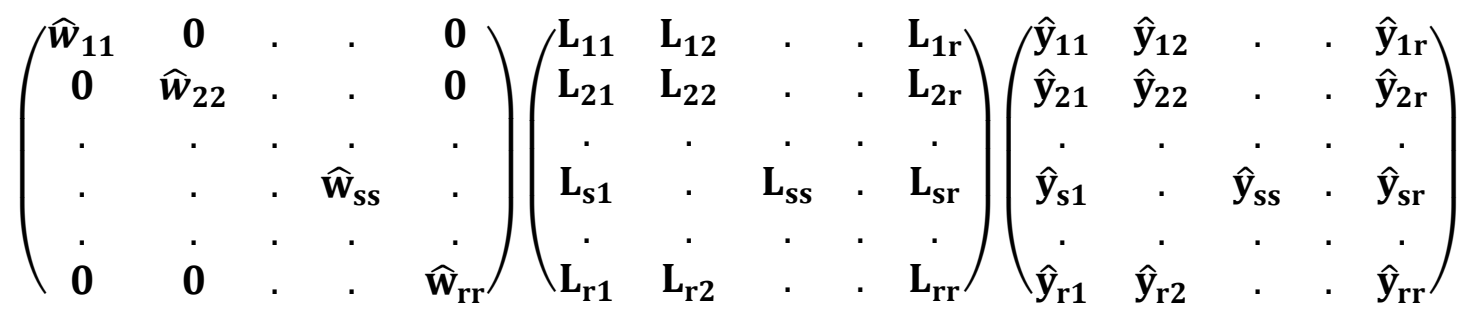

Matrix $\mathbf{W}$ informs on all the embodied water flows in the global economy associated to the good and services traded among countries and domestically consumed in each nation. Each of the block matrices $\boldsymbol{W}_{\boldsymbol{r} \boldsymbol{s}}$ in $\mathbf{W}$ is composed of $w_{r s}^{i j}$ elements that capture the water directly and indirectly consumed in sector $i$ of country $r$ to meet the final demand of sector $j$ in country s.

From equation (3), it is possible to calculate all the relevant variables for our study. Firstly, summing by rows we obtain the water consumed by each country measured from the producer responsibility approach, or DW ( $d w_{s}$ in (4)). DW shows the water directly consumed in the production activities of country s. It can be decomposed into two elements. First, the volume of domestic resources that meet internal demands of country $s$ (Domestic) expressed as $w_{s}^{d o m}$ in equation (4). Second, virtual water exports (VWX) that capture the water resources consumed in $s$ and embodied in the products exported to other countries $r(r \neq s)$ and represented as $v w x_{s}$ in (4). Analytically, being e a vector of ones, it can be expressed as:

$d w_{s}=\sum_{r} \mathbf{e}^{\prime} \mathbf{W}_{\mathbf{s r}} \mathbf{e}=\mathbf{e}^{\prime} \mathbf{W}_{\mathbf{s s}} \mathbf{e}+\sum_{r \neq s} \mathbf{e}^{\prime} \mathbf{W}_{\mathbf{s r}} \mathbf{e}=w_{s}^{d o m}+v w x_{s}$

Similarly, summing by columns, we get the water consumption of countries accounted from the consumption responsibility approach or the WF ( $w f_{s}$ in equation (5)). It describes the water directly and indirectly consumed in every country to meet 
its own final demand regardless whether water resources are domestic or external. The external component of the WF is known as virtual water imports (VWM) and reflects the water embodied in the goods and services consumed in $s$ but produced outside the borders of the country and is expressed as $v w m_{s}$ in (5). Subsequently, the WF can be obtained as:

$w f_{s}=\sum_{r} \mathbf{e}^{\prime} \mathbf{W}_{\mathbf{r s}} \mathbf{e}=\mathbf{e}^{\prime} \mathbf{W}_{\mathbf{s s}} \mathbf{e}+\sum_{r \neq s} \mathbf{e}^{\prime} \mathbf{W}_{\mathbf{r s}} \mathbf{e}=w_{s}^{d o m}+v w m_{s}$

Additionally, it is possible to obtain the virtual water trade balance (VWTB), i.e., the gap between VWM and VWX, as follows:

$v w t b_{s}=w f_{s}-d w_{s}=\sum_{r \neq s} \mathbf{e}^{\prime} \mathbf{W}_{\mathbf{r s}} \mathbf{e}-\sum_{r \neq s} \mathbf{e}^{\prime} \mathbf{W}_{\mathbf{s r}} \mathbf{e}=v w m_{s}-v w x_{s}$

Note that, at the country level, this is exactly the difference between the consumption (WF) and production approach (DW) applied to water resources. This allows us to define a country $s$ as a net importer of embodied water when VWM are higher than VWX, or similarly, when the WF exceeds DW. It indicates that the pressures exerted on foreign water resources are higher than the impacts on domestic water as a result of international trade. On the contrary, $s$ is net exporter of water if VWX are larger than VWM or DW exceeds WF.

Matrix $\mathbf{W}$ is estimated for the 41 areas contained in the WIOD. However as the main goal of this study is to examine water consumption dynamics in the EU27, we select the specific information refereeing to its 27 members. Then, an extensive descriptive analysis is carried out focusing on the variables estimated using the MRIO model in order to characterised the main trends at the European, country and sector levels.

Turning to the econometric analysis, our approach relies on panel data techniques given the characteristics of the WIOD that provides detailed information on a crosssection of countries over several time periods. This methodology allows us to control for individual country heterogeneity alongside studying the dynamics of adjustment of water resources. We are interested in analysing the impact of variables that change over time (i.e., GDP) focusing on a specific set of countries (i.e., EU27), and in particular, differences over time between the predictor and outcome variables within those countries. On the other hand, each country has its own (un)observed individual characteristics, considering that EU members have different economic, structural and technological patterns, which might influence the predictor variables and need to be 
control for. In this regard, the Fixed Effects (FE) model, also known as the within estimator, is designed to study the causes of changes within an entity (e.g., countries) providing consistent results (Clark and Linzer, 2015). FE estimation removes those time invariant characteristics by eliminating the average differences between countries prior to estimation -the between variation, so we can assess the net effect of the corresponding regressors on the outcome variables. Thus the coefficient estimates exploit the variation within the countries. Moreover, the FE model controls for all time-invariant differences between the countries, so the estimated coefficients cannot be biased because of omitted time-invariant characteristics. We will further include time effects in our estimation to control for any unexpected variation or special events that may affect the outcome variables. ${ }^{1}$

We now explain the estimation strategy that allows us to estimate the effect of country-specific changes in GDP per capita on country-specific changes in DW (and the other outcome variables of interest obtained in equations (4) and (5), i.e., WF, Domestic, VWX and VWM). Specifically, we estimate the model:

$\operatorname{Ln}(D W / P)_{i t}=\alpha_{i}+\gamma_{t}+\beta_{1} \operatorname{Ln}(G D P / P)_{i t}+\beta_{2}[\operatorname{Ln}(G D P / P)]_{i t}^{2}+\varepsilon_{i t}$

where $\alpha_{i}$ are the country fixed effects that capture unobservable time invariant country characteristics, and $\gamma_{t}$ are the year fixed effects that capture events common to all countries. The parameter estimate $\beta_{1}$ reflects the marginal effect that country specific changes in GDP per capita have on country specific changes in DW, and $\beta_{2}$ shows second order effects allowing for potential non-linear effects of GDP per capita. $\varepsilon_{i t}$ represents the idiosyncratic error term that is clustered at the country level thus might be serially correlate within countries.

\section{Results}

\subsection{Descriptive analysis}

Most of the relevant literature (Vörösmarty et al., 2005; Wang et al., 2016; WWAP, 2015) points at population growth and economic development as the main drivers of

\footnotetext{
1 Relevant references covering panel data econometrics are Hsiao (2003), Wooldridge (2010) and Baltagi (2013), among others. A full technical exposition can be found in Arellano (2003).
} 
water consumption. This hypothesis holds when all available countries in our sample are considered at once. Water consumption has gradually increased worldwide from 1995 to 2008 . Growing at $1.9 \%$ every year, it virtually mimics the trend followed by per capita GDP in the period.

Figure 1 represents the dynamics of the DW and WF indicators and the trajectory followed by per capita income in six different regions, considered as representative of water consumption patterns worldwide. Moreover, using equation (6) it is possible to determine the path described by the VWTB that helps establishing specific trade patterns. At first glance two conclusions can be reached. First, developing areas such as China, Brazil and Russia show growing DW and WF that follow the trend displayed by per capita GDP. Besides, the three of them appear as net exporters of embodied water during the period, remaining the gap between VWX and VWM quite stable in China and Brazil, and closing down in Russia. Second, in high-income areas, which appear as net importers of water, the trajectories of water consumption and per capita GDP do not match. As income gradually grows, DW slows down in the 2000s reaching a turning point. In the case of Australia and USA it does also happen for the WF. Notwithstanding, the EU27 has experienced a significant decline in the DW from the beginning of the twenty-first century, but depicts a gradual increase in the WF. Although DW would indicate that from 2001 Europe was growing without corresponding increases in water pressures, the WF draws the opposite conclusion. These facts highlight the need of considering both the production- and consumptionbased approaches when looking for the links between economic development and environmental pressures.

Focusing on the EU27, the consumption of water resources for production activities (DW) slightly increased between 1995 and 2008, showing an annual growth rate of 0.46\%. As depicted in Figure 1, this growth was particularly intense until 2001 decreasing afterwards at $1.36 \%$ every year, and notably diverging from the positive and vigorous increase in per capita income (1.65\%). The deceleration of DW was mainly driven by the decline in Domestic water consumption, since VWX displayed a pacy growth for the entire period (2.76\% average annual growth rate). In sum, although the EU27 kept consuming domestic water resources for exports, it was the decline in the consumptive use to meet internal demand that made DW to flatten. 

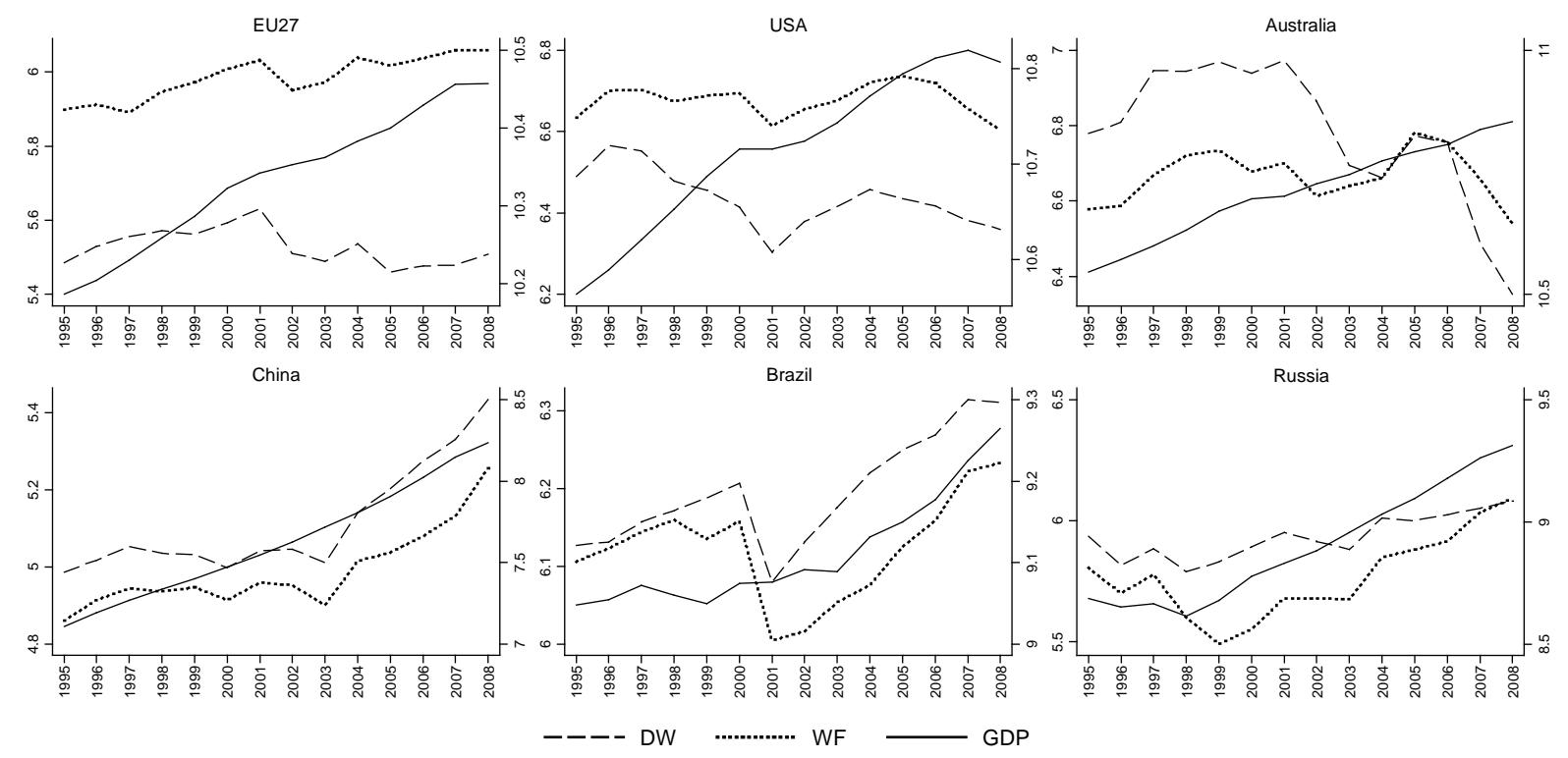

Figure 1: Trends in DW, WF and GDP from 1995 to 2008 in six different world regions. Variables are expressed in per capita and logs. DW and WF are represented in the left hand-side vertical axis. GDP is shown in the right hand-side vertical axis. The horizontal axis depicts the time span.

This picture, as we have previously indicated, is completely different when we measure water consumption from the consumption-based approach, i.e., using WF, showing between 1995 and 2008 a yearly average growth of 1.53\%. Yet the Domestic component was decreasing moderately between 2001 and 2008, the increment of the WF was totally driven by the increase in VWM that grew at 3.15\% during the same period. Hence, EU27 were gradually externalising water consumption by substituting the consumption of domestic with foreign water resources to satisfy their final demands for consumption and investment. Along this line, Figure 1 indicates that EU27 behaves as a net importer of water resources, i.e., VWM were larger than VWX. This indicates that the water resources embodied in EU27 imports from the rest of the world exceeded the volume of internal water consumed to produce goods and services exported outside the borders of the EU27. This pattern has tended to strengthen as the gap between VWM and VWX substantially widens at the end of the period. On average, net imports grew at 3.3\% yearly.

Looking at the contributions by industry classification (based on the NACE rev. 1 in WIOD tables), three sectors were driving the increase in DW in the EU27 between 1995 and 2008: Agriculture, Hunting, Forestry and Fishing, Chemicals and Other Manufactures (Table 1). Specifically, the chemicals sector DW growth was particularly intense, growing at $4.4 \%$ every year. Considering the consumption 
responsibility, these sectors also contributed to the growth in the European WF although their shares were significantly lower. This can be explained by the indirect water consumption coming from sectors that have strong economic linkages with them such as the Food Industry, Hotels and Restaurants or Construction, among others. Their shares on total WF ranged from 5.3\% (Hotels and Restaurants) to 20\% (Other Services as Health and Social Work).

Table 1: Change $(\Delta)$ and contribution to change (\%) in EU27 DW and WF by sectors, 1995-2008.

\begin{tabular}{lrrrr}
\hline & DW & \multicolumn{1}{c}{ WF } \\
\hline & $\Delta\left(10^{6} \mathrm{~m}^{3}\right)$ & $\%$ & $\Delta\left(10^{6} \mathrm{~m}^{3}\right)$ & $\%$ \\
\hline Agriculture, Hunting, Forestry and Fishing & 4,314 & 60.1 & 6,242 & 16.3 \\
Food, Beverages and Tobacco & 428 & 6.0 & 5,427 & 14.2 \\
Textiles and Textile Products & 9 & 0.1 & 1,049 & 2.7 \\
Construction & 0 & 0.0 & 2,410 & 6.3 \\
Hotels and Restaurants & 0 & 0.0 & 2,008 & 5.3 \\
Electricity, Gas and Water Supply & 174 & 2.4 & -19 & -0.1 \\
Other Manufactures & 818 & 11.4 & 7,723 & 20.2 \\
Trade and transport & 0 & 0.0 & 2,392 & 6.3 \\
Other Services & 0 & 0.0 & 7,243 & 19.0 \\
Mining, Quarrying, Coke, Petroleum, Nuclear Fuel & 0 & 0.0 & 1,837 & 4.8 \\
Chemicals and Chemical Products & 1,440 & 20.0 & 1,888 & 4.9 \\
TOTAL & 7,183 & 100.0 & 38,199 & 100.0 \\
\hline
\end{tabular}

At the country level most of the growth in DW consumption between 1995 and 2008 took place in Spain (representing 85\% of the change in total EU27 DW), Italy and Finland. As Figure 2 shows, these countries (as well as others such as Romania and Poland) increased the consumption of domestic water endowment to meet foreign (VWX), and internal demands (Domestic). The growth was particularly intense if we look at the external component, for instance VWX rose yearly at 6\% in Spain. More concretely, DW was boosted by the Electrical sector in Finland and Italy (see Figure A2); whilst in Spain the Agricultural sector (highly intensive in blue water resources given the importance of irrigation) was behind this change. The specific economic activities of these areas also boosted the impact on water resources measured with the consumption-based approach contributing up to 44\% to the EU27 WF growth.

On the other hand, areas such as France, Portugal and Greece depict a decreasing DW indicator. The fall in the domestic component comes as the explanatory factor for the first two countries, whereas in Greece both the domestic consumption (that accounts for $84 \%$ of the decline) and VWX were triggering this trajectory. Figure A2 shows how both the Agriculture and Electricity sectors were behind this fall in Portugal and 
Greece, but only the latter in the case of France. In per capita terms, Cyprus experienced the largest fall in DW (mostly associated to Agriculture) decreasing by $286 \mathrm{~m}^{3} / \mathrm{P}$ from 1995 to 2008. This is far from other Mediterranean countries such as Portugal and Greece where the fall was about $96 \mathrm{~m}^{3} / \mathrm{P}$ and $84 \mathrm{~m}^{3} / \mathrm{P}$, respectively (see Figure A1).
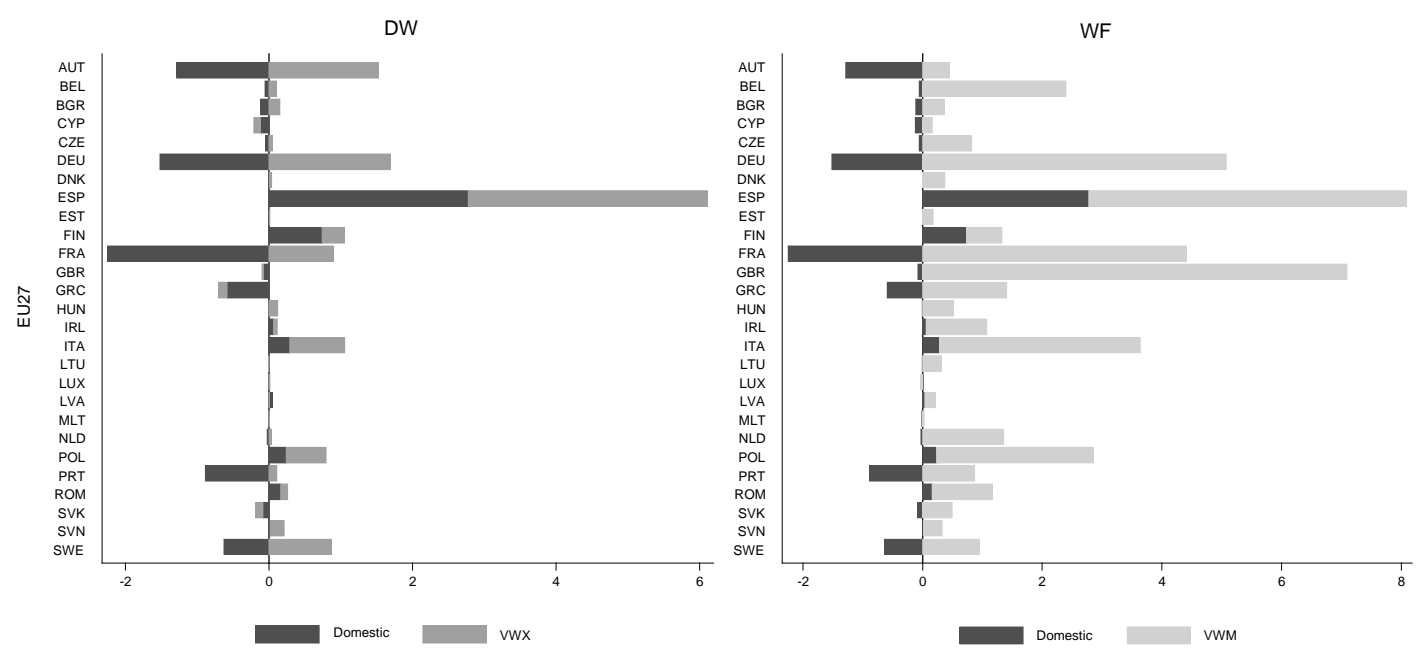

Figure 2: Change in DW $\left(\mathrm{km}^{3}\right)$ and WF $\left(\mathrm{km}^{3}\right)$ of the EU27 by domestic and trade components (VWX and VWM), 1995-2008

Looking at the WF, Spain (21\%), Great Britain (18\%), Italy (10\%) and Germany (9\%) were the most significant contributors to its increase. This growth was mostly driven by VWM that increased in every EU state but Luxembourg, chiefly in eastern countries. For instance, VWM soared in Poland and Romania, growing at $9.1 \%$ and 8.4\% every year, respectively. Furthermore, countries such as Germany and Great Britain were notably substituting the consumption of domestic water resources with VWM (see Figure 2). At the sector level, Manufactures and the Electricity determined this variation in Germany, and the Hotels and Restaurants as well as Other Services also entailed a considerable increase in the UK WF. In relative terms, as Figure A1 shows, Finland, Ireland and Belgium stand out with an increase in per capita WF of around $200 \mathrm{~m}^{3} / \mathrm{P}$. All these areas also depicted a significant growth in VWM per capita. In other countries such as Austria, Luxembourg and Portugal the WF slightly fell. This can be explained by the fall of the domestic component (except for Luxembourg) related to the Electricity sector since VWM kept growing. In relative terms, Luxembourg experienced the highest fall in the WF per capita during the period 1995-2008, accounting for about $200 \mathrm{~m}^{3} / \mathrm{P}$ (see Figure A1). 
Overall, the WF experienced a higher increase than DW basically due to the upsurge in VWM during these years (see Figure 1). From this perspective, not only was the agricultural sector that triggered the increase in water consumption, as we can also observe important pressures exerted by the Food Industry, Construction, the Hotel and Restaurants sectors or Other Manufactures and Services (see the case of Spain and Italy in Figure A2). Finally, considering population (Figure A1), Finland, Slovenia, Spain and Latvia displayed the largest increase in DW. From 1995 to 2008 each Finish citizen directly increased water consumption by $172 \mathrm{~m}^{3} / \mathrm{P}$, about twice as much as the absolute growth in Spain and Slovenia.

In 2008, all European countries but Sweden and Austria were net importers of blue water (see Figure A3). Despite VWX kept growing during the period 1995-2008 in most nations, the increase in VWM has been so intense that widened the gap between VWM and VWX. This indicates that the trend towards the externalisation of environmental pressures on water has strengthened and seems to be common in most EU27 areas. Our data suggests that this trajectory has been especially intense in developed areas such as Great Britain, France and Germany, which together contributed around $45 \%$ to the increase in net VWM. When considering population, this pattern is very strong in Belgium, Cyprus and Ireland. Finally, we find very insightful facts looking at VWM by the origin of water (Figure A3). Firstly, on average, $80 \%$ of the water embodied in the imports of EU27 members comes from non-European areas. From 1995 to 2008, this trend intensified in the most developed areas in the EU27, where the share of VWM from the rest of the world rose. On the contrary, the contribution of VWM from EU27 to total VWM increased in lowincome areas. As an example, about $94 \%$ of the rise in the Danish VWM was due to the increase in imports from non-EU27. This figure declines if we look at Hungary, although it still represents around 59\%. As for VWX, the pattern was the opposite. EU27 mostly exported water embodied within the EU, on average representing between $60 \%$ and $65 \%$ of total VWX in EU27. The growth within EU27 VWX was to a large extent driven by low-income countries such as Romania, where the increase in VWX to EU27 represented 76\% of the rise in Romanian total VWX. The former results go in line with the findings of a recent study on intra-European agricultural virtual water trade flows (Antonelli et al., 2017).

\subsection{Estimation results and discussion}


We start our analysis by checking for the presence of linear relationships amongst our indicators. Table 2 shows the pairwise correlation coefficients for each of our outcome variables and GDP. All variables are expressed in logs and per capita terms. Results clearly indicate that VWM and WF are strongly correlated with GDP whereas VMX and GDP show a rather moderate relation. On the other hand, the association with GPD is small for DW and practically non-existent for Domestic water.

Table 2: Pairwise correlations.

\begin{tabular}{|c|c|c|c|c|c|}
\hline & DW & WF & Domestic & VWX & VWM \\
\hline GDP & $0.202^{* * *}$ & $0.708^{* * *}$ & 0.092 & $0.329^{* * *}$ & $0.932^{* * *}$ \\
\hline
\end{tabular}

Visual inspection of the data is useful to clarify the existence of linear relationships, thus Figure 2 shows the corresponding scatterplots. The left hand panel displays the results for DW and its components, Domestic and VWX, and the right hand panel the results for WF and its components, Domestic and VWM, with GDP. The scatterplot shows a definite positive linear relationship between WF and GPD that is mainly driven by VWM. The moderate linear relationship between DW and GDP is also driven by VMX. There appears to be no relation between the Domestic water consumption and income. These descriptive results reinforce the relevant role of trade when analysing impacts on water resources, and show the importance of considering both the production and consumption-based methodologies to obtain meaningful estimates. 

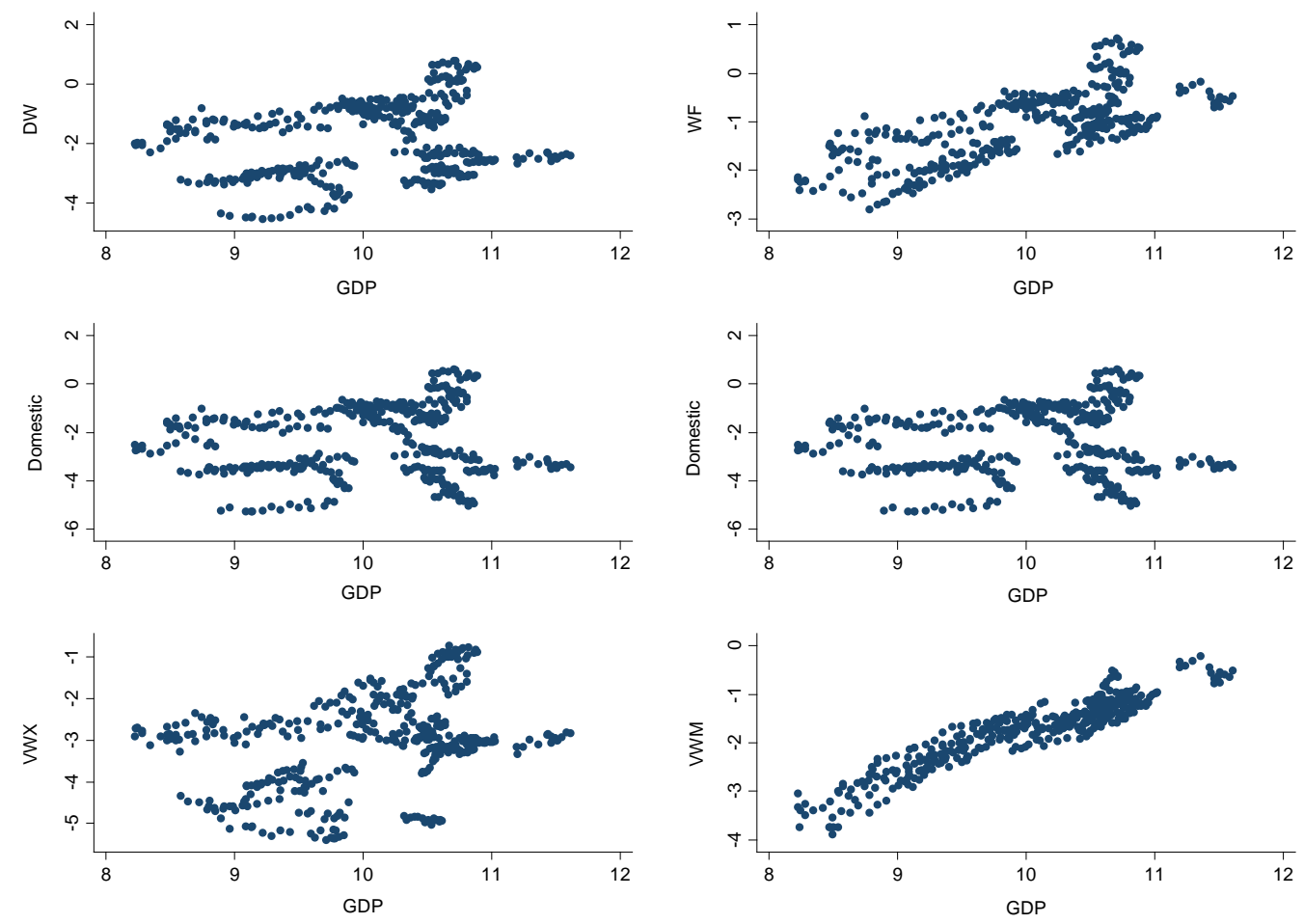

Figure 3: Scatter plots. GDP versus water indicators (DW, WF, Domestic, VWX and VWM). All the variables are in logs and per capita terms.

While we begin our analysis by using descriptive techniques to explore the general characteristics of our data, we aim to identify and measure effects associated to the dynamics of adjustment of water resources. Table 3 summarises the findings of the link between within-country variation in GDP per capita and within-country variation in water indicators allowing for possible nonlinear covariate effects. All variables are expressed in logs and per capita terms. We present estimates corresponding to equation (7) using panel-corrected-standard-errors least square estimation that accounts for heteroskedastic and contemporaneously correlated disturbances across panels, and including country fixed effects as well as year fixed effects in all specifications.

Columns (1)-(7) of Table 3 show the corresponding point estimates on our GDP measure that are mostly significant at the $1 \%$ level. The point estimates in columns (1)-(2) show the positive link between the main water indicators considering both the production and consumption-based perspectives, and economic growth, implying that a 1\% increase in GDP increases DW and WF by 1.17 and 2.64 per cent respectively. Columns (3)-(7) refer to the main components associated to water indicators covering both intra- and extra-EU trade flows to account for potential differences in trade 
patterns. Regarding the production-based approach, GDP affects trade variables in opposite directions increasing intra-EU exports, by 3.22\%, and decreasing exports to non-European countries by $2.52 \%$. On the other hand, increases in the WF are clearly driven by the positive effect of GDP in both intra- and extra-EU imports, accounting for 7.16 and $4.94 \%$ respectively. Finally, GDP and Domestic water are positively related also contributing to the increase of the water indicators.

Table 3: Estimation results.

\begin{tabular}{lccccccc}
\hline & DW & WF & Domestic & $\begin{array}{c}\text { Intra-EU } \\
\text { VWX }\end{array}$ & $\begin{array}{c}\text { Extra-EU } \\
\text { VWX }\end{array}$ & $\begin{array}{c}\text { Intra-EU } \\
\text { VWM }\end{array}$ & $\begin{array}{c}\text { Extra-EU } \\
\text { VWM }\end{array}$ \\
\hline GDP & $1.169 * *$ & $2.642^{* * *}$ & $2.035^{* * *}$ & $3.227^{* * *}$ & $-2.516^{* * *}$ & $7.158^{* * *}$ & $4.943^{* * *}$ \\
& $(0.537)$ & $(0.615)$ & $(0.621)$ & $(0.736)$ & $(0.718)$ & $(0.596)$ & $(0.851)$ \\
GDP $^{2}$ & -0.0314 & $-0.0998^{* * *}$ & $-0.0684^{*}$ & $-0.158^{* * *}$ & $0.135^{* * *}$ & $-0.320^{* * *}$ & $-0.222^{* * *}$ \\
& $(0.0300)$ & $(0.0347)$ & $(0.0351)$ & $(0.0402)$ & $(0.0409)$ & $(0.0335)$ & $(0.0480)$ \\
\hline Observations & 378 & 378 & 378 & 378 & 378 & 378 & 378 \\
Adjusted $\mathrm{R}^{2}$ & 0.990 & 0.973 & 0.991 & 0.974 & 0.974 & 0.977 & 0.968 \\
\hline $\begin{array}{l}\text { Notes: }{ }^{*} p<0.1,{ }^{* *} p<0.05,{ }^{* * *} p<0.01 \text {. All the variables are in logs and per capita terms. Corrected standard errors for } \\
\text { correlation and heteroskedasticity in parentheses. All specifications include year and country fix effects. }\end{array}$
\end{tabular}

These findings highlight the effects of belonging to a supranational organisation suggesting that EU countries have tightened their commercial ties alongside economic growth, which also have a significant impact on the consumption of water resources. As GDP grows water embodied into products for intra-EU exports have increased thus positively affecting DW, whereas extra-EU export flows that satisfy external demand using European resources have declined. The trade pattern from the consumption side follows a similar trend regarding the increment of intra-EU imports, showing also positive effects when we consider imports from non-European countries. Nevertheless, the contribution of water embodied into imported products amongst European countries to the WF, conditioned on GDP, is about $40 \%$ higher compared to imports coming from non-European countries, which reinforces the idea of stronger commercial connections within the EU.

At this point, it is important to further consider the dynamics of the formation of the EU where countries with different economic, structural and technological characteristics have joined in at different points of time. These differences are reflected in the heterogeneity of EU members as countries at particular stages of economic progress develop their economics at different rates, and therefore have distinct trends of consumption, production and trade patterns. Thus, it is reasonable to 
expect that the effect of GDP on our water indicators might differ depending on the country economic development.

Table 4: Estimation results for high-income and low-income EU27.

\begin{tabular}{|c|c|c|c|c|c|c|c|}
\hline & DW & WF & Domestic & $\begin{array}{c}\text { Intra-EU } \\
\text { VWX }\end{array}$ & $\begin{array}{c}\text { Extra-EU } \\
\text { VWX }\end{array}$ & $\begin{array}{c}\text { Intra-EU } \\
\text { VWM }\end{array}$ & $\begin{array}{c}\text { Extra-EU } \\
\text { VWM }\end{array}$ \\
\hline \multicolumn{8}{|c|}{ High-income countries } \\
\hline GDP & $\begin{array}{c}-8.729 * * * \\
(2.036)\end{array}$ & $\begin{array}{c}17.22 * * * \\
(2.766)\end{array}$ & $\begin{array}{l}-2.679 \\
(2.836)\end{array}$ & $\begin{array}{c}-12.26^{* * *} \\
(2.446)\end{array}$ & $\begin{array}{c}-19.14^{* * *} \\
(2.497)\end{array}$ & $\begin{array}{c}8.996^{* * *} \\
(1.972)\end{array}$ & $\begin{array}{c}29.90 * * * \\
(3.862)\end{array}$ \\
\hline $\mathrm{GDP}^{2}$ & $\begin{array}{c}0.409 * * * \\
(0.0939)\end{array}$ & $\begin{array}{c}-0.780 * * * \\
(0.128)\end{array}$ & $\begin{array}{c}0.132 \\
(0.130)\end{array}$ & $\begin{array}{c}0.542 * * * \\
(0.113)\end{array}$ & $\begin{array}{c}0.898^{* * *} \\
(0.116)\end{array}$ & $\begin{array}{c}-0.379 * * * \\
(0.0869)\end{array}$ & $\begin{array}{c}-1.376 * * * \\
(0.181)\end{array}$ \\
\hline Observations & 189 & 189 & 189 & 189 & 189 & 189 & 189 \\
\hline Adjusted R ${ }^{2}$ & 0.995 & 0.962 & 0.994 & 0.986 & 0.987 & 0.960 & 0.898 \\
\hline \multicolumn{8}{|c|}{ Low-income countries } \\
\hline GDP & $\begin{array}{c}2.249 * * \\
(1.045)\end{array}$ & $\begin{array}{c}1.521 \\
(0.997)\end{array}$ & $\begin{array}{c}3.408^{* * *} \\
(1.214)\end{array}$ & $\begin{array}{l}2.961^{*} \\
(1.620)\end{array}$ & $\begin{array}{c}-5.073^{* * *} \\
(1.335)\end{array}$ & $\begin{array}{c}8.931 * * * \\
(1.174)\end{array}$ & $\begin{array}{c}2.848^{* *} \\
(1.359)\end{array}$ \\
\hline $\mathrm{GDP}^{2}$ & $\begin{array}{l}-0.0878 \\
(0.0588)\end{array}$ & $\begin{array}{l}-0.0294 \\
(0.0566)\end{array}$ & $\begin{array}{l}-0.133^{*} \\
(0.0685)\end{array}$ & $\begin{array}{l}-0.156^{*} \\
(0.0909)\end{array}$ & $\begin{array}{c}0.246^{* * *} \\
(0.0768)\end{array}$ & $\begin{array}{c}-0.438 * * * \\
(0.0671)\end{array}$ & $\begin{array}{l}-0.0991 \\
(0.0769)\end{array}$ \\
\hline Observations & 189 & 189 & 189 & 189 & 189 & 189 & 189 \\
\hline Adjusted $\mathrm{R}^{2}$ & 0.987 & 0.965 & 0.988 & 0.973 & 0.963 & 0.969 & 0.960 \\
\hline
\end{tabular}

We explore this question in Table 4, examining the possibility that those effects are not homogeneous for all countries, by splitting our sample into high- and low-income countries. Results confirm the presence of heterogeneity on the effect of GDP, especially for high-income countries, where the impact of GDP is now negatively associated to DW, generating a decrease of $8.73 \%$. We also find that within-country increases in GDP continue to exhibit statistically significant and quantitatively large positive effects on within-country changes in the consumption of water resources as measured from the consumption side, increasing the WF by 17.22 per cent.

Regarding the main components of both the production and consumption-based water indicators, we observe that the adverse effect of economic growth on DW is totally driven by the significant fall in VMX, around $12.26 \%$ within the EU and $19.14 \%$ to non-European countries. On the other hand, the substantial raise in the WF associated to higher levels of GDP works mainly through the large and significant increases of intra- and extra-EU VWM, accounting for 9 and 30 per cent respectively. Furthermore, the magnitude of the effect of GDP on Domestic consumptive water, which measures the consumption of country resources to satisfy only the internal 
demand, is certainly small and statistically insignificant indicating that for highincome countries the change in water indicators is rather based on within country variation in trade patterns. Therefore, these findings suggest that both VMX and VWM are the main channels through which within-country variation in GDP per capita affects within-country variation in water indicators.

Turning to the analysis of low-income countries we observe a different pattern. Increases in GDP show a moderate positive relation with DW, of the magnitude of 2.25 per cent, and no statistically significant relation with the WF. The positive impact of economic growth measured from the production-based approach is mediated by the increase generated in intra-EU VMX, which accounts for 2.96\%, alongside raises in domestic consumptive water by 3.41\%, although extra-EU VWX have declined in 5.1 per cent. Looking at the consumption side, the corresponding point estimates reflect how increments in GDP have stimulated both intra- and extraEU VWM that grow at 8.93 and 2.85\% respectively, despite rendering insignificant effects in the level of water resources embodied in all products utilize to satisfy the internal demand.

\section{Conclusions}

In this paper we analyse the links between economic development and relevant water indicators, including precise information on their main components, for the EU27 during the period from 1995 to 2008. We claim it is necessary to consider both production- and consumption-based approaches to correctly identify and measure the effects associated to the anthropogenic dynamics of water resources, and thus reduce the risk to end up with an incomplete and potential misleading interpretation of water pressures. In this regard, we use MRIO methodology that further allows consideration of domestic impacts and associated trade relations. Furthermore, obtaining consistent estimates of the effect that GDP changes have on water indicators is complicated by difficult to measure and often unobservable country heterogeneity. We use panel fixed effects regressions to address these issues.

Our main results indicate that the effects differ substantially depending on whether the production- or consumption-based approach are used for measurement, especially when we conditioned on the country's economic development. These differences are not only related to the magnitude of the income effect, but also lead to opposite 
trajectories of water consumption. In particular, high-income areas show that withincountry increases in GDP have quantitatively large positive effects on within-country changes in the WF, and at the same time the impact of GDP is negatively associated to DW. On the other hand, low-income countries follow a different pattern where GDP growth shows a moderate positive link with DW and practically plays no role determining changes in the consumption of water resources as measured from the consumption side.

Moreover, the analysis of the main components associated to water indicators highlight the role of VMX and VWM as the transmission mechanisms of the main effects. Thus, in contrast to the more economically advanced partners, low-income EU countries show that GDP growth contributes to establish closer commercial relations within the EU. This pattern holds to the extent that water consumption incorporated into products for intra-EU exports have increased alongside domestic consumptive water, thus increasing DW. However, notwithstanding the foregoing, our estimates suggest that the positive link between within-country variation in GDP and within-country variation in the WF is associated to high-income countries, working mainly through the large increase in water consumption incorporated into imported products to satisfy their increasing internal demand. Hence, indicating that the growth path followed by the most developed areas in the EU27 is based on the externalisation of the environmental burden over the less developed European partners, and external developing countries.

The major findings of this paper stress that studies considering only a productionbased perspective to assess impacts of economic growth on the environment will be underestimating the externalisation effect, and therefore providing an incomplete analysis of the situation that may lead to misleading conclusions. These results are consistent with the concerns raised by Jackson, (2009) regarding the measurement error associated to trade flows when resources used to manufacture products abroad are not considered. This is especially relevant for modern developed economies that tend to move progressively away from domestic manufacturing as GDP grows. Therefore, the macro water governance should better include both perspectives in the elaboration of new management policies. First, analysis concerning water pressures offshoring will draw from the consumption approach, which will also indicate the regional/country dependence on foreign water resources. Second, the production 
approach analysis will provide relevant information for designing strategies that aim to maximise economic and social welfare as well as minimise environmental impacts.

Furthermore, our empirical results suggest that the relationship between GDP and water pressures varies with different levels of economic development within EU27, which is of enormous relevance when setting strategies for water management. Policies that determine consumption, production and trade patterns have been long governed by economic factors, thus relegating environmental criteria. For example, the agricultural subsidies prevalent in developed countries, such as the Common Agricultural Policy (CAP) in the EU, mostly benefited irrigation agriculture although it is highly intensive in blue water consumption. Future scenarios will be limited by the (uncertain) sustainability of the growth pattern followed by the actual EU27 and its subsequent environmental impacts. The growing offshoring of water pressures, mostly from high-income areas, together with the expected growth of the least developed countries, urge for the implementation of integrated water resources management. On the policy front, in line with the recommendation of the "Blueprint to Safeguard Europe’s Water Resources” (European Comission, 2012), our results suggest that the coordination of water management with the EU social and economic strategies would enhance the sustainability of water systems alongside regional development. In addition, it might be of interest to evaluate whether home-grown initiatives for creating such coordinated policies are more or less effective in water resource administration than supranational initiatives.

In a highly globalized context, with local impacts becoming global through supply chains, institutional coordination at the national, supranational and global levels is essential. A joint design and implementation of specific technological, economic, and social policies and environmental regulations appears as the most feasible way to achieve sustainable economic growth while conserving water resources.

\section{Acknowledgements}

This work has been partially supported by the Ministry of Economy and Industry of the Spanish Government, project ECO2016-74940-P and the Department of Science, Technology and Universities of the Government of Aragon (Research Group “Agrifood "Growth and Demand and Natural Resources”). 


\section{References}

Allan, J.A., 1993. Fortunately There Are Substitutes for Water Otherwise Our Hydropolitical Futures Would Be Impossible, Priorities for Water Resources Allocation and Management, in: Overseas Development Administration. London, UK, pp. 13-26.

Antonelli, M., Tamea, S., Yang, H., 2017. Intra-EU agricultural trade, virtual water flows and policy implications. Sci. Total Environ. 587-588, 439-448. doi:10.1016/j.scitotenv.2017.02.105

Arellano, M., 2003. Panel Data Econometrics: Advanced Texts in Econometrics. Oxford University Press.

Baltagi, B.H., 2013. Econometric Analysis of Panel Data, 5th Editio. ed. Wiley.

Cazcarro, I., Duarte, R., Sánchez-Chóliz, J., 2012. Water Flows in the Spanish Economy: Agri-Food Sectors, Trade and Households Diets in an Input-Output Framework. Environ. Sci. Technol. 46, 6530-6538. doi:10.1021/es203772v

Chen, Z.-M., Chen, G.Q., 2013. Virtual water accounting for the globalized world economy: National water footprint and international virtual water trade. Ecol. Indic. 28, 142-149. doi:10.1016/j.ecolind.2012.07.024

Clark, T.S., Linzer, D.A., 2015. Should I Use Fixed or Random Effects? Polit. Sci. Res. Methods 3, 399-408. doi:DOI: 10.1017/psrm.2014.32

Cole, M.A., 2004. Economic growth and water use. Appl. Econ. Lett. 11, 1-4. doi:10.1080/1350485042000187435

Dietzenbacher, E., Los, B., Stehrer, R., Timmer, M., de Vries, G., 2013. The construction of world input-output tables in the WIOD project. Econ. Syst. Res. 25, 71-98. doi:10.1080/09535314.2012.761180

Duarte, R., Pinilla, V., Serrano, A., 2013. Is there an environmental Kuznets curve for water use? A panel smooth transition regression approach. Econ. Model. 31, 518-527. doi:10.1016/j.econmod.2012.12.010

European-Commission, 2012. A Blueprint to Safeguard Europe’s Water Resources. Brussels.

Galli, A., Iha, K., Halle, M., El Bilali, H., Grunewald, N., Eaton, D., Capone, R., Debs, P., Bottalico, F., 2017. Mediterranean countries' food consumption and sourcing patterns:An Ecological Footprint viewpoint. Sci. Total Environ. 578, 383-391. doi:10.1016/j.scitotenv.2016.10.191

Galli, A., Weinzettel, J., Cranston, G., Ercin, E., 2013. A Footprint Family extended MRIO model to support Europe's transition to a One Planet Economy. Sci. Total Environ. 461, 813-818. doi:10.1016/j.scitotenv.2012.11.071

Genty, A., Arto, I., Neuwahl, F., 2012. Final database of environmental satellite accounts: Technical report on their compilation, WIOD Deliverable 4.6.

Gilmont, M., 2016. Analysing the economic development impact of semi-arid lands, and mitigation through food-trade water resource decoupling.

Gilmont, M., 2015. Water resource decoupling in the MENA through food trade as a mechanism for circumventing national water scarcity. Food Secur. 7, 1113. doi:10.1007/s12571-015-0513-2 
Gupta, S., 2015. Decoupling: A step toward sustainable development with reference to OECD countries. Int. J. Sustain. Dev. World Ecol. 22. doi:10.1080/13504509.2015.1088485

Hoekstra, A.Y., Chapagain, A.K., Aldaya, M.M., Mekonnen, M.M., 2011. The water footprint assessment manual: Setting the global standard. Earthscan, London, UK.

Hoekstra, A.Y., Hung, P.Q., 2002. Virtual water trade: A quantification of virtual water flows between nations in relation to international crop trade, Value of Water Research Report Series. IHE, Delft, The Netherlands.

Hsiao, C., 2003. Analysis of Panel Data:, 2nd ed. Cambridge University Press, Cambridge. doi:10.1017/CBO9780511754203

Jackson, T., 2009. Prosperity without Growth: Economics for a Finite Planet. Earthscan Publications, London, UK.

Katz, D., 2015. Water use and economic growth: reconsidering the Environmental Kuznets Curve relationship. J. Clean. Prod. 88, 205-213. doi:10.1016/j.jclepro.2014.08.017

Krausmann, F., Gingrich, S., Eisenmenger, N., Erb, K.-H., Haberl, H., FischerKowalski, M., 2009. Growth in global materials use, GDP and population during the 20th century. Ecol. Econ. 68, 2696-2705. doi:10.1016/j.ecolecon.2009.05.007

Leontief, W., 1941. The structure of American economy 1919-1939 : An empirical application of equilibrium analysis. Oxford University Press, Oxford, UK.

Lutter, S., Pfister, S., Giljum, S., Wieland, H., Mutel, C., 2016. Spatially explicit assessment of water embodied in European trade: A product-level multi-regional input-output analysis. Glob. Environ. Chang. 38, 171-182. doi:10.1016/j.gloenvcha.2016.03.001

Miglietta, P., De Leo, F., Toma, P., 2016. Environmental Kuznets curve and the water footprint: An empirical analysis. Water Environ. J. in press. doi:10.1111/wej.12211

Naqvi, A., Zwickl, K., 2017. Fifty shades of green: Revisiting decoupling by economic sectors and air pollutants. Ecol. Econ. 133, 111-126. doi:10.1016/j.ecolecon.2016.09.017

Proops, J.L.R., 1988. Energy intensities, input-output analysis and economic development. University of Keele, Dept.of Economics., Keele, UK.

Sebri, M., 2015. Testing the environmental Kuznets curve hypothesis for water footprint indicator: a cross-sectional study. J. Environ. Plan. Manag. 59, 1-24. doi:10.1080/09640568.2015.1100983

Serrano, A., Guan, D., Duarte, R., Paavola, J., 2016. Virtual Water Flows in the EU27: A Consumption-based Approach. J. Ind. Ecol. 20, 547-558.

Smil, V., 2008. Energy in Nature and Society: General Energetics of Complex Systems. The MIT Press, Cambridge, MA.

Steen-Olsen, K., Weinzettel, J., Cranston, G., Ercin, A.E., Hertwich, E.G., 2012. Carbon, land, and water footprint accounts for the european union: Consumption, production, and displacements through international trade. Environ. Sci. 
Technol. 46, 10883-10891.

Steinberger, J.K., Krausmann, F., Getzner, M., Schandl, H., West, J., 2013. Development and Dematerialization: An International Study. PLoS One 8, e70385.

Stern, D.I., 2010. Between estimates of the emissions-income elasticity. Ecol. Econ. 69, 2173-2182. doi:10.1016/j.ecolecon.2010.06.024

Timmer, M.P., Dietzenbacher, E., Los, B., Stehrer, R., de Vries, G.J., 2015. An Illustrated User Guide to the World Input-Output Database: the Case of Global Automotive Production. Rev. Int. Econ. 23, 575-605. doi:10.1111/roie.12178

Tukker, A., Dietzenbacher, E., 2013. Global multiregional input-output frameworks: an introduction and outlook. Econ. Syst. Res. 25, 1-19. doi:10.1080/09535314.2012.761179

UN-Water, 2006. Coping with water scarcity: a strategic issue and priority for system-wide action.

UNEP, 2011. Decoupling Natural Resource Use and Environmental Impacts from Economic Growth. Report of the Working Group on Decoupling to the International Resource Panel.

Vanham, D., Bidoglio, G., 2013. A review on the indicator water footprint for the EU28. Ecol. Indic. 26, 61-75. doi:10.1016/j.ecolind.2012.10.021

Vörösmarty, C.J., Leveque, C., Revenga, C., 2005. Fresh Water, in: Frank Rijsberman, Robert Costanza, Jacobi, P. (Eds.), Millennium Ecosystem Assessment, Volume 1: Conditions and Trends Working Group Report. Island Press, pp. 165-207.

Wang, R., Hertwich, E., Zimmerman, J.B., 2016. (Virtual) Water Flows Uphill toward Money. Environ. Sci. Technol. 50, 12320-12330. doi:10.1021/acs.est.6b03343

Wang, R., Zimmerman, J., 2016. Hybrid Analysis of Blue Water Consumption and Water Scarcity Implications at the Global, National, and Basin Levels in an Increasingly Globalized World. Environ. Sci. Technol. 50, 5143-5153. doi:10.1021/acs.est.6b00571

WMO, 1997. Comprehensive Assessment of the Freshwater Resources of the World. Geneva, Switzerland.

Wooldridge, J.M., 2010. Econometric Analysis of Cross Section and Panel Data. MIT Press.

WorldBank, 2016. World Development Indicators. World Bank.

WWAP, 2015. The United Nations World Water Development Report 2015: Water for a Sustainable World. UNESCO, Paris.

Zhao, C., Chen, B., 2014. Driving Force Analysis of the Agricultural Water Footprint in China Based on the LMDI Method. Environ. Sci. Technol. 48, 12723-12731. doi:10.1021/es503513z

Ziolkowska, J.R., Ziolkowski, B., 2016. Effectiveness of Water Management in Europe in the 21st Century. Water Resour. Manag. 30, 2261-2274. doi:10.1007/s11269-016-1287-9 


\section{Appendix}

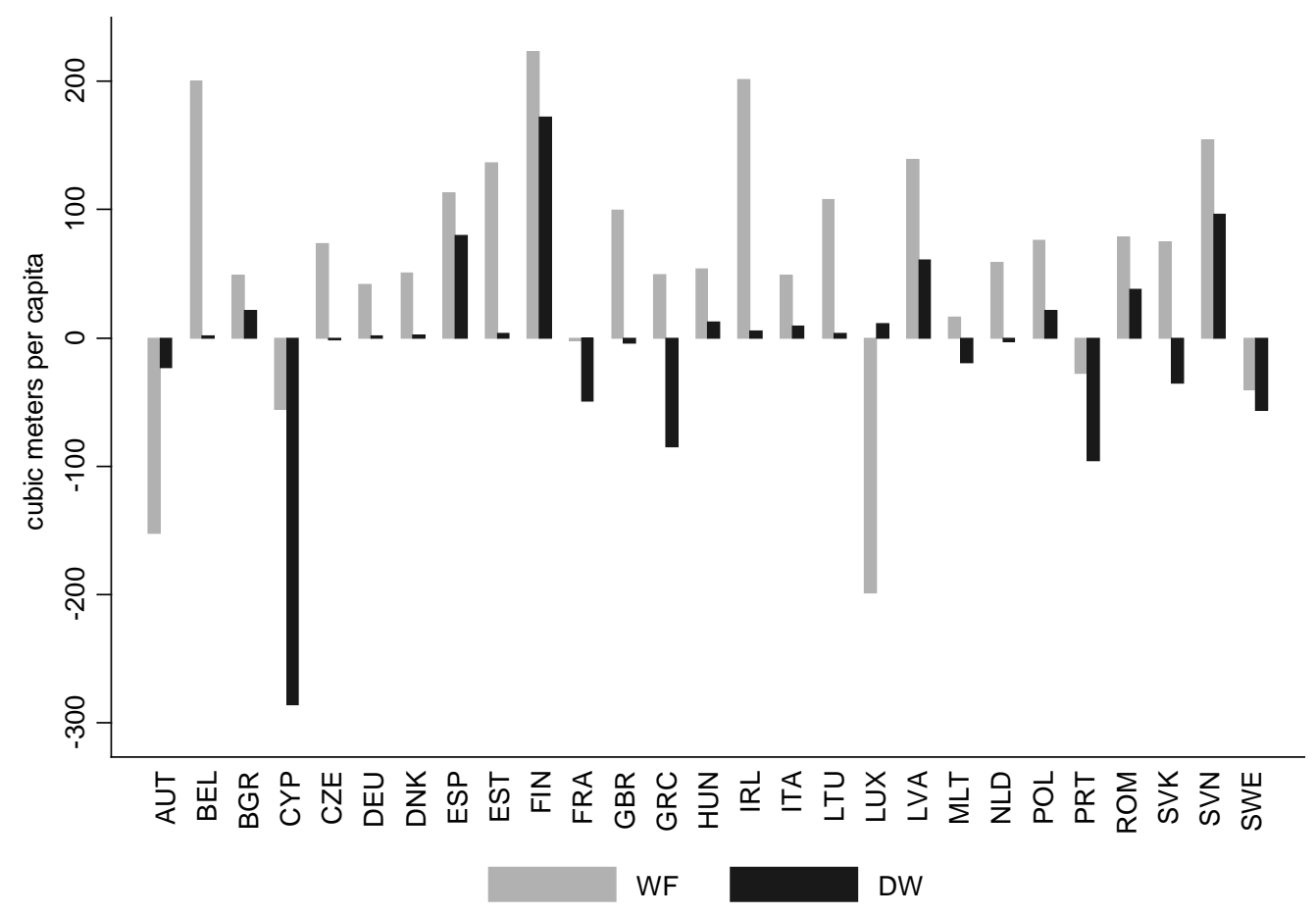

Figure A1: Change in DW $\left(\mathrm{m}^{3} / \mathrm{P}\right)$ and WF $\left(\mathrm{m}^{3} / \mathrm{P}\right)$ in the EU27, 1995-2008 

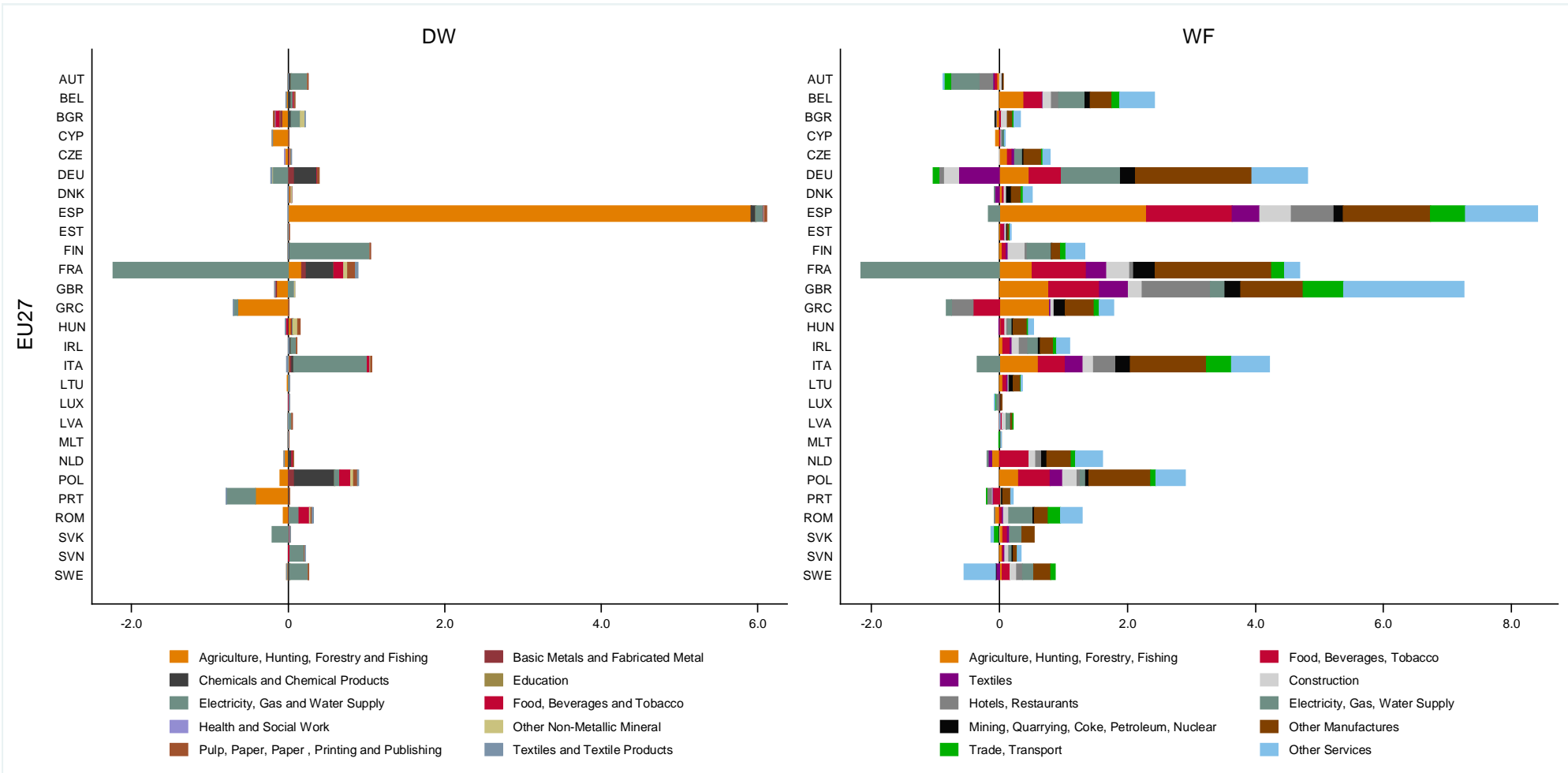

Figure A2: Change in DW ( $\left.\mathrm{km}^{3}\right)$ and WF $\left(\mathrm{km}^{3}\right)$ of the EU27 by sectors, 1995-2008 


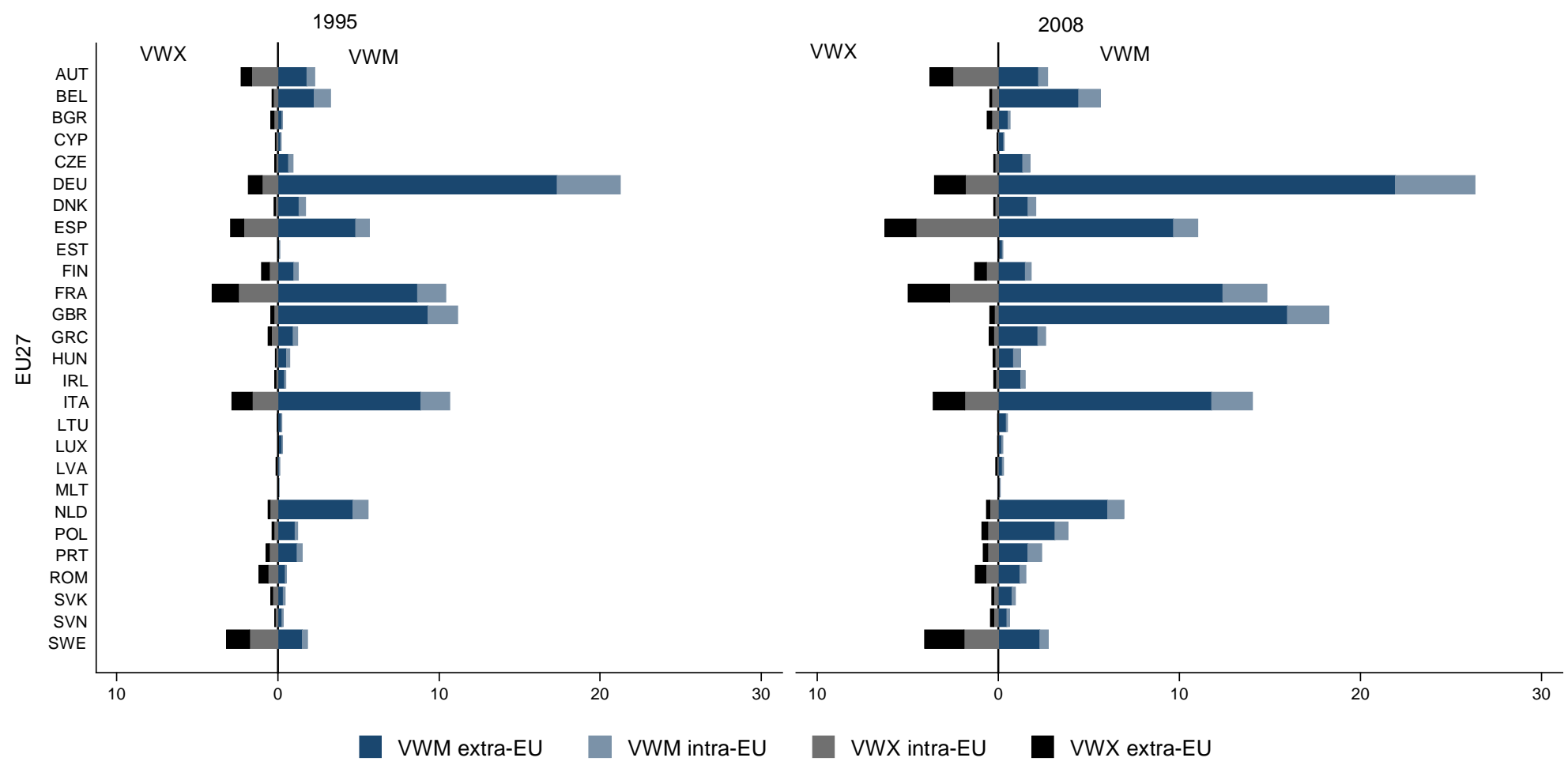

Figure A3: VWX $\left(\mathrm{km}^{3}\right)$ and VWM $\left(\mathrm{km}^{3}\right)$ of the EU27, 1995 and 2008 


\section{Sectors included in WIOD and classification}

Agriculture, Hunting, Forestry and Fishing

Food, Beverages and Tobacco

Textiles and Textile Products

Construction

Hotels and Restaurants

Electricity, Gas and Water Supply

Mining and Quarrying

Chemicals and Chemical Products

Other Manufactures: Leather, Leather and Footwear, Wood and Products of Wood and Cork, Pulp, Paper, Paper , Printing and Publishing, Coke, Refined Petroleum and Nuclear Fuel, Rubber and Plastics, Other Non-Metallic Mineral, Basic Metals and Fabricated Metal, Machinery, Nec, Transport Equipment, Electrical and Optical Equipment, Manufacturing, Nec; Recycling

Trade and Transport: Sale, Maintenance and Repair of Motor Vehicles and Motorcycles; Retail Sale of Fuel, Wholesale Trade and Commission Trade, Except of Motor Vehicles and Motorcycles, Retail Trade, Except of Motor Vehicles and Motorcycles; Repair of Household Goods, Inland Transport, Water Transport, Air Transport

Other Services: Other Supporting and Auxiliary Transport Activities; Activities of Travel Agencies, Post and Telecommunications, Financial Intermediation, Real Estate Activities, Renting of M\&Eq and Other Business Activities, Public Admin and Defence; Compulsory Social Security, Education, Health and Social Work, Other Community, Social and Personal Services, Private Households with Employed Persons 
List of countries included in WIOD

\begin{tabular}{|c|c|c|}
\hline ISOCODE & Country name & $\begin{array}{r}\begin{array}{r}\text { Average per capita GDP } \\
\text { (constant 2010US\$) }\end{array} \\
\end{array}$ \\
\hline \multicolumn{3}{|c|}{ EU27 } \\
\hline AUT & Austria & 42,456 \\
\hline BEL & Belgium & 40,695 \\
\hline BGR & Bulgaria & 4,892 \\
\hline CYP & Cyprus & 28,032 \\
\hline CZE & Czech Republic & 16,342 \\
\hline DEU & Germany & 38,283 \\
\hline DNK & Denmark & 55,898 \\
\hline ESP & Spain & 28,941 \\
\hline EST & Estonia & 12,005 \\
\hline FIN & Finland & 41,480 \\
\hline FRA & France & 38,531 \\
\hline GBR & Great Britain & 35,938 \\
\hline GRC & Greece & 25,170 \\
\hline HUN & Hungary & 11,368 \\
\hline IRL & Ireland & 43,759 \\
\hline ITA & Italy & 35,942 \\
\hline LTU & Lithuania & 8,754 \\
\hline LUX & Luxembourg & 92,015 \\
\hline LVA & Latvia & 8,767 \\
\hline MLT & Malta & 17,450 \\
\hline NLD & Netherlands & 46,055 \\
\hline POL & Poland & 9,177 \\
\hline PRT & Portugal & 21,188 \\
\hline ROM & Romania & 6,148 \\
\hline SVK & Slovak Republic & 12,008 \\
\hline SVN & Slovenia & 19,974 \\
\hline SWE & Sweden & 45,893 \\
\hline \multicolumn{3}{|c|}{ Non EU27 } \\
\hline AUS & Australia & 45,489 \\
\hline BRA & Brazil & 9,172 \\
\hline CAN & Canada & 43,933 \\
\hline $\mathrm{CHN}$ & China & 2,311 \\
\hline IDN & Indonesia & 2,420 \\
\hline IND & India & 903 \\
\hline JPN & Japan & 40,984 \\
\hline KOR & Republic of Korea & 16,555 \\
\hline MEX & Mexico & 8,395 \\
\hline RUS & Russian Federation & 7,731 \\
\hline TUR & Turkey & 8,374 \\
\hline USA & United States & 45,339 \\
\hline TWN & Taiwan & Not available \\
\hline RoW & Rest of the World & Not available \\
\hline
\end{tabular}

